\title{
Performance analysis of LMS based control algorithm for power quality improvement in three phase grid connected system for linear/non-linear load
}

\author{
Mohmmad Ahmad, Sheeraz Kirmani \\ Department of Electrical Engineering, Jamia Millia Islamia, New Delhi, India
}

\section{Article Info \\ Article history: \\ Keywords: \\ DSTATCOM, \\ LMS \\ Power quality \\ TH \\ VSC}

Received Mar 6, 2019

Revised Apr 20, 2019

Accepted Jul 8, 2019

\begin{abstract}
This paper presents the adaptive filtering based least mean square control algorithm for distribution static compensator (DSTATCOM) in three-phase grid tied system for linear/non-linear load, to solve the power quality problems caused by solid-state equipment and devices. This is shown that the active component weights obtained from the load currents in the LMS adaptive filter are used to produce the reference currents and subsequently produces the switching pulses for VSC of the compensator. The complete circuit along with the adaptive technique and diode bridge rectifier type nonlinear load is simulated in Matlab/Simulink software. Initially the circuit was simulated for a three phase linear inductive load. Later it was simulated for a rectifier load connected at PCC with a disconnection of the load of any phase for a short duration of time. It is concluded that the harmonics are found within the limit. The harmonics and power results for both types of loads are compared in a tabular form. Hence this three phase system with DSTATCOM improves the power quality in the three-phase distribution network therefore, serves to provide harmonics reduction, load balancing and regulating the terminal voltage at the point of common coupling (PCC).
\end{abstract}

Copyright $(2019$ Institute of Advanced Engineering and Science. All rights reserved.

\section{Corresponding Author:}

Mohmmad Ahmad,

Research Scholar,

Department of Electrical Engineering,

Jamia Millia Islamia, New Delhi, India 110025.

Email: ahmadbtech@gmail.com

\section{INTRODUCTION}

The invention of solid-state devices and its new technologies have made the life very simple and peaceful. On the other hand, these devices-based load deteriorate the power quality. The problems related to Power quality become of major concern in distribution system which results in reduction of efficiency of the entire system and hence requires more attention to reduce power pollution. There are large numbers of solidstate devices based nonlinear loads which inject the harmonics into the entire system and subsequently decrease the quality of power. These loads are renewable energy systems, HVDC system, medical equipment, office and household equipment, transmission, high-frequency transformers, electric traction, arc furnaces, etc., If the system consists of unbalanced single-phase or three-phase loads, the nature of waveforms in the distribution system is changed, leads to affects the equipment as well as nearby users. Nowadays, research is concentrated on power quality issues like mitigation of current quality problems such as harmonics elimination, power factor correction (PFC), load balancing, noise cancellation and the voltage quality problems like swells, sag, voltage unbalances, impulses and fluctuations etc.

The solution of these current based and voltage-based power quality problems is to use alternatives in the system which are Distribution static compensator (D-STATCOM), Dynamic voltage restore (DVR), and universal power quality conditioner (UPQC) [1]. Voltage-source converter (VSC)-based DSTATCOM is 
the suitable option to mitigate all current based power quality problems, a major concern, in addition to static VAR compensators, power capacitors etc., the existing mitigating technologies. This device supplies the appropriate compensation into the system by which a balance sinusoidal current is generated. There are various topologies of DSTATCOM available in literature and the application of this finds in Microgrid [2], Distributed generation [3]. The compensation capability of distributed static compensator is dependant mainly on the control techniques used [4-7]. DSTATCOM is widely used in both the power network i.e. Three phase three wire and three phase four wire system [8].

To operate the VSC based DSTATCOM, requiring the appropriate pulses, a proper control algorithm is needed. This algorithm may be design either in time domain or frequency domain depending on the type of pulse generating process. The switching pulses for the VSC can be generated by extracting reference source/grid current and then comparing these with observed supply currents. Different configuration and various control algorithms are well explained in literature [9-12]. These techniques are such as: Unit template, synchronous rotating frame (SRF) theory, instantaneous reactive power theory (IRPT), power balance theory (PBT), single PQ theory, Adaline based Neural network, single DQ theory etc.

Adaptive filter theory shows its power to track the changes of the unknown systems' environment and characteristics. The filter parameters will be self-adjusted during the environment changing so that the filter behaviour and environment will be order to fulfil its purpose. There exists various adaptive controlbased algorithm available in the literature such as recursive least square (RLS), Least Mean Square (LMS) etc. [13-14]. Among these algorithms, LMS and its variants become popular for their best convergence speed and stability [15-18]. The function of LMS algorithm is to extract accurate pulse and minimizes the error appropriately for the proper operation of DSTATCOM.

In this paper, continuous time LMS based adaptive control algorithm with DSTATCOM system will be discuss to improve current related power quality problems, harmonics' elimination, load balancing of nonlinear loads etc. Moreover, this filter structure is simple, and to get desired response, only one constant is required.

\section{SYSTEM CONFIGURATION}

The block diagram of the DSTATCOM system with three phase system having a non-linear load connected at a PCC is shown in Figure 1. The distribution system consists of a three phase grid of $415 \mathrm{~V}$ (line to line), $50 \mathrm{~Hz}$, having $\mathrm{R}_{\mathrm{s}}$ and $\mathrm{L}_{\mathrm{s}}$ as series resistance and inductance respectively, along with IGBT based Voltage Source Converter (VSC), dc link capacitance $\left(\mathrm{C}_{\mathrm{dc}}\right)$, an interfacing inductance $\mathrm{L}_{\mathrm{f}}$ between VSC and PCC to reduce the ripples in compensating current, and ripple filter $\mathrm{R}_{\mathrm{f}}$ and $\mathrm{C}_{\mathrm{f}}$ to suppress the high switching frequency noise [19]. VSC is a three-leg voltage source inverter having six IGBT switches with an input as dc voltage source and the output as three phase ac supply feeding to the grid as well as to the linear/nonlinear load connected at PCC. The system is analyzed for both the load, linear and non-linear loads. Inductive RL load is employed as linear load at PCC, while as a non-linear load, a three-phase diode bridge rectifier with inductive branch at dc side, is used.

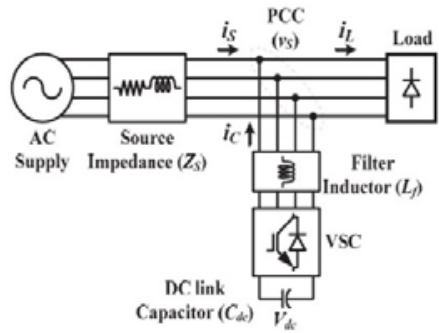

Figure 1. Block diagram of DC bus based DSTATCOM with three phase system

\section{CONTROL ALGORITHM}

The schematic diagram of DSTATCOM based on Least Mean Square (LMS) control algorithm is shown in Figure 2. The main function of this algorithm is to derive unit templates for each of the three phases $\left(\mathrm{x}_{\mathrm{aa}}, \mathrm{x}_{\mathrm{ab}}\right.$ and $\left.\mathrm{x}_{\mathrm{ac}}\right)$ extracted from the observed grid voltages $\left(\mathrm{v}_{\mathrm{sa}}, \mathrm{v}_{\mathrm{sb}}\right.$ and $\left.\mathrm{v}_{\mathrm{sc}}\right)$, required grid reference current by sensing the three phase load current $\left(i_{L a}, i_{L b}\right.$ and $\left.i_{L c}\right)$, grid voltage magnitude $\left(V_{t}\right)$ and $V_{d c}$ across the VSC. The switching pulses for DSTATCOM are generated after making a comparison between the two grid currents: reference current obtained from algorithm and the observed current from the system.

Performance analysis of LMS based control algorithm for power quality ... (Mohmmad Ahmad) 


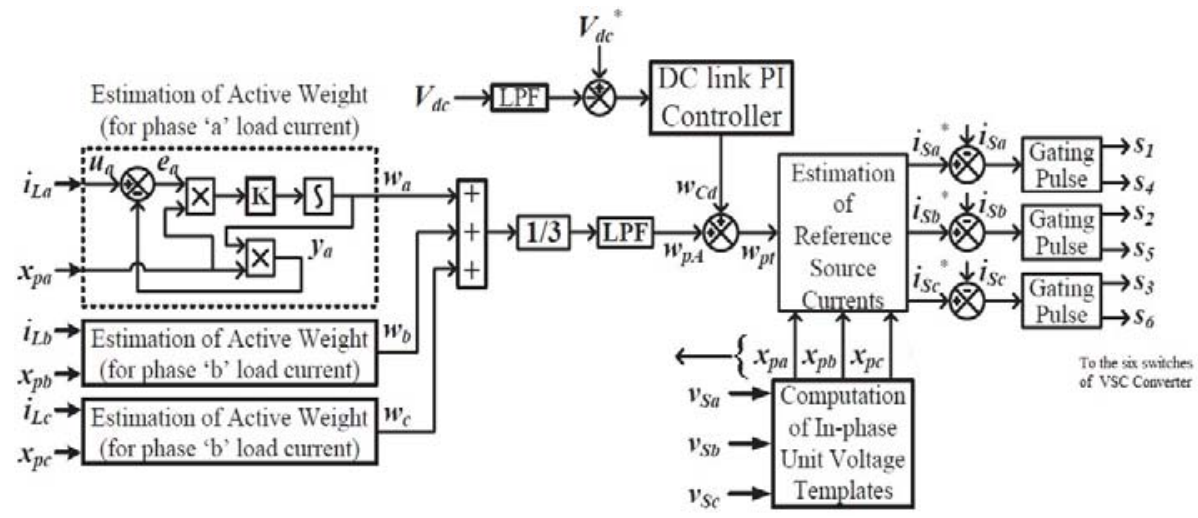

Figure 2. Schematic diagram for LMS based control algorithm

Initially the active or in-phase voltage unit templates of each of three phases $\mathrm{x}_{\mathrm{aa}}, \mathrm{x}_{\mathrm{ab}}$ and $\mathrm{x}_{\mathrm{ac}}$ can be calculated with the help of grid voltage magnitude $\left(\mathrm{V}_{t}\right)[20]$. These $\mathrm{x}_{\mathrm{pa}}, \mathrm{x}_{\mathrm{pb}}$ and $\mathrm{x}_{\mathrm{pc}}$ are in phase with the three phase grid voltages $\mathrm{v}_{\mathrm{sa}}, \mathrm{v}_{\mathrm{sb}}$ and $\mathrm{v}_{\mathrm{sc}}$ and mathematically these are represented as:

$$
x_{p a}=\frac{v_{s a}}{V_{t}}, x_{p b}=\frac{v_{s b}}{V_{t}}, x_{p c}=\frac{v_{s c}}{V_{t}}
$$

$\mathrm{V}_{\mathrm{t}}$ is the magnitude of the three phase instantaneous supply voltages given as:

$$
V_{t}=\sqrt{\frac{2}{3}\left(v_{s a}^{2}+v_{s b}^{2}+v_{s c}^{2}\right.}
$$

where instantaneous three phase voltages are:

$$
\begin{aligned}
& v_{s a}(t)=V_{m} \operatorname{Sin} \omega t \\
& v_{s b}(t)=V_{m} \operatorname{Sin}\left(\omega t-120^{\circ}\right) \\
& v_{s c}(t)=V_{m} \operatorname{Sin}\left(\omega t-240^{\circ}\right)
\end{aligned}
$$

Three blocks are used to estimate active weight component related to each of the three phases. Each block receives the input signal as a load current. The difference between the input and output is termed as error signal while the output is obtained after the multiplication of unit in phase template ( $\mathrm{x}_{\mathrm{pa}}$ for phase ' $\mathrm{a}$ ') with its corresponding weight component. Moreover, the integrated output of the product of unit template and error along with gain is known as active component of load current for a particular phase. The equations for phase ' $a$ ' representing the above in time domain are written in (4).

$e_{a}(t)=i_{L a}(t)-y_{a}(t)$

Where output $y_{a}(t)=w_{a}(t) \cdot x_{p a}(t)$

$w_{a}=k \int_{0}^{t} e_{a}(t) \cdot x_{p a}(t) d t$

Similarly, for phase ' $b$ ' and phase ' $c$ ', the active weight components ( $\mathrm{w}_{\mathrm{b}}$ and $\mathrm{w}_{\mathrm{c}}$ ) can be calculated. The average of active weights for all the three phases will be taken to ensure balance source current. This is stated as $\mathrm{w}_{\mathrm{pA}}$ and value will be:

$$
w_{p A}(t)=\frac{w_{a}+w_{b}+w_{c}}{3}
$$

The dc link voltage of VSC is sensed with reference dc voltage to get error. Consequently, this error is feed to Proportional plus Integral controller (PI) of dc bus voltage to get dc loss weight component ( $\left.\mathrm{w}_{\mathrm{cd}}\right)$ and the equation is written as [21-22]:

$$
w_{c d}(k+1)=w_{c d}(k)+k_{p}\left[v_{d d}(k+1)-v_{d d}(k)\right]+k_{i} \cdot v_{d d}(k+1)
$$


where

$$
v_{d d}(k+1)=v_{d c}^{*}(k+1)-v_{d c}(k+1)
$$

$\mathrm{k}_{\mathrm{p}}$ and $\mathrm{k}_{\mathrm{d}}$ are the proportional and integral gain for the dc voltage controller, while $\mathrm{v}_{\mathrm{dd}}(\mathrm{n}+1)$ is the error between dc reference value and the sensed value of $d c$ bus.

Therefore, one can obtain the total active weight component by adding average active weight component and dc loss component which is stated as:

$$
w_{p t}=w_{p A}+w_{c d}
$$

The reference grid currents of the three phases can be obtained by multiplying total active weight components with corresponding unit templates for each phase. These are representing as:

$$
i_{s a}^{*}=w_{p t} \cdot x_{p a}, i_{s b}^{*}=w_{p t} \cdot x_{p b}, i_{s c}^{*}=w_{p t} \cdot x_{p c}
$$

Then, the actual grid currents are compared with the reference grid current for each phase. The differences of these two currents are again compared individually with a reference signal, a triangular carrier wave of $10 \mathrm{kHz}$. By this comparison, the six pulses are extracted $\left(\mathrm{S}_{1}\right.$ to $\left.\mathrm{S}_{6}\right)$ which are utilized as the gate signal of six switches of the three-arm voltage source converter.

\section{RESULTS AND DISCUSSION}

The performance of a control circuit with a linear R-L load is shown in Figure 3, where the load of phase ' $\mathrm{a}$ ' is disconnected from time 0.5 to 0.6 second. The variation of grid voltage at PCC $\left(\mathrm{v}_{\mathrm{s}}\right)$, source currents of the three phases $\left(i_{s}\right)$, load current for three phases $\left(i_{L}\right)$ and the compensator current $\left(i_{C}\right)$ are shown in the figure. Moreover, the active and reactive power of load, source and compensator is also represented in Figure 4.

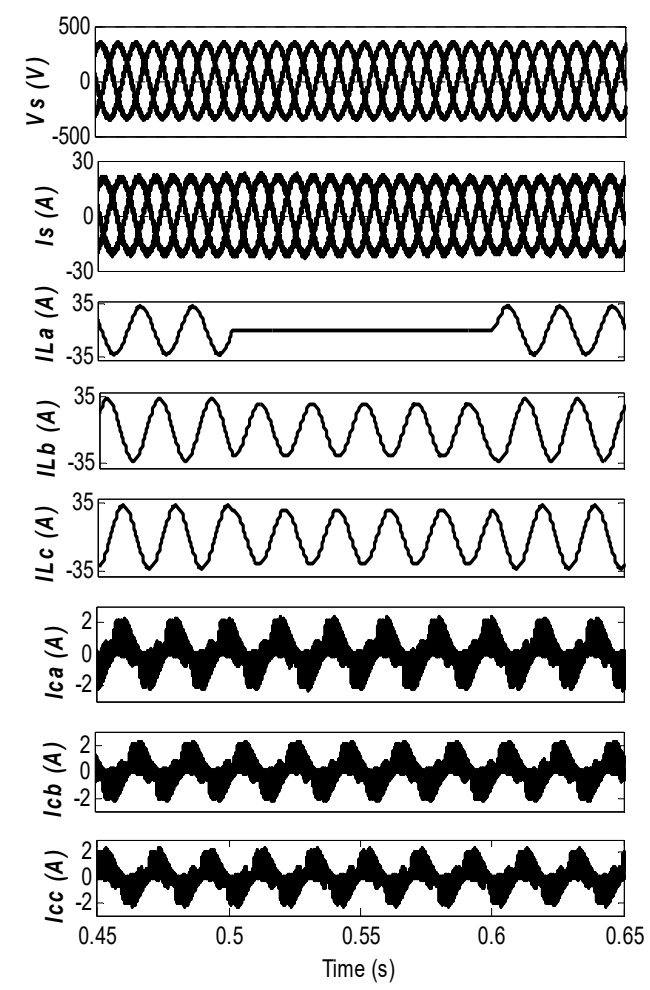

Figure 3. Variation of different currents for linear load with load disconnection of phase a between 0.5 to $0.6 \mathrm{~s}$

Performance analysis of LMS based control algorithm for power quality ... (Mohmmad Ahmad) 
Further, the control circuit is analyzed for a non-linear load of a diode bridge with R-L branch connected at its dc side. The performance of this system is depicted in Figure 5 when the phase ' $a$ ' load is disconnected from 0.5 to 0.6 second. This figure consists of source/grid voltage at PCC $\left(\mathrm{v}_{\mathrm{s}}\right)$, grid current $\left(\mathrm{i}_{\mathrm{s}}\right)$, output $\left(\mathrm{y}_{\mathrm{a}}\right)$, error signal $\left(\mathrm{e}_{\mathrm{a}}\right)$, active components' average weight $\left(\mathrm{w}_{\mathrm{avg}}\right)$, weight component corresponds to PI controller's output $\left(\mathrm{w}_{\mathrm{cd}}\right)$, active components total weight $\left(\mathrm{w}_{\mathrm{pt}}\right)$ and $\mathrm{dc}$ bus voltage $\left(\mathrm{V}_{\mathrm{dc}}\right)$. Moreover, the waveforms of load current as well as compensator current along with grid voltage, current is represented in Figure 6.

The active and reactive power for source/grid, load and compensator is also shown in Figure 7. It is concluded from the figure that the active power to the load $\left(\mathrm{P}_{\mathrm{L}}\right)$ is mainly supplied from the grid as active power $\left(\mathrm{P}_{\mathrm{S}}\right)$, whereas the reactive power into the load is majorly supplied by compensator as reactive power.

A comparison of different parameters is made between linear as well as non-linear load and is shown in Table 1. It is clear from the table that, for linear load, the harmonics are less in grid/source voltage, source current and load current as compare to the harmonics obtained in the case of non-linear load. The harmonics present in source current are $5 \%$ and $6.9 \%$ for linear and non-linear load respectively. While the harmonics in load current are $0.1 \%$ and $29.5 \%$ for linear and non-linear load of bridge rectifier respectively. Further, it can also be seen from the table that, as the load changes from linear to non-linear, the load power and source power changes slightly, while the compensator power remains approximately the same.

Table 1. Comparison of different parameters for linear and non-linear load

\begin{tabular}{|c|c|c|c|c|c|c|c|c|c|c|c|c|}
\hline \multirow[b]{2}{*}{ Load Type } & \multicolumn{2}{|c|}{$\begin{array}{c}\text { Source Voltage } \\
\text { (Vs) }\end{array}$} & \multicolumn{2}{|c|}{$\begin{array}{l}\text { Source current } \\
\text { (A) }\end{array}$} & \multicolumn{2}{|c|}{$\begin{array}{l}\text { Load Current } \\
\text { (A) }\end{array}$} & \multicolumn{2}{|c|}{ Source Power } & \multicolumn{2}{|c|}{ Load Power } & \multicolumn{2}{|c|}{$\begin{array}{l}\text { Compensator } \\
\text { Power }\end{array}$} \\
\hline & $\begin{array}{l}\text { RMS } \\
\text { value } \\
\text { (V) }\end{array}$ & $\begin{array}{l}\text { THD } \\
(\%)\end{array}$ & $\begin{array}{l}\text { RMS } \\
\text { value }\end{array}$ & $\begin{array}{l}\text { THD } \\
(\%)\end{array}$ & $\begin{array}{l}\text { RMS } \\
\text { value }\end{array}$ & $\begin{array}{c}\text { THD } \\
(\%)\end{array}$ & $\begin{array}{l}\mathrm{Ps}_{\mathrm{s}} \\
(\mathrm{W})\end{array}$ & $\begin{array}{c}\text { Qs } \\
\text { (VAr) }\end{array}$ & $\begin{array}{l}\mathrm{P}_{\mathrm{L}} \\
(\mathrm{W})\end{array}$ & $\begin{array}{c}\mathrm{Q}_{\mathrm{L}} \\
(\mathrm{VAr})\end{array}$ & $\begin{array}{c}\mathrm{P}_{\mathrm{C}} \\
(\mathrm{W})\end{array}$ & $\begin{array}{c}\mathrm{Q}_{\mathrm{c}} \\
\text { (VAr) }\end{array}$ \\
\hline Linear & 413.3 & 3.5 & 26.0 & 5.0 & 31.1 & 0.1 & 18230 & 171 & 20700 & 4064 & 54 & -539 \\
\hline Non linear & 413.4 & 3.8 & 26.4 & 6.9 & 31.2 & 29.5 & 18200 & 255 & 20900 & 447 & 54 & -540 \\
\hline
\end{tabular}
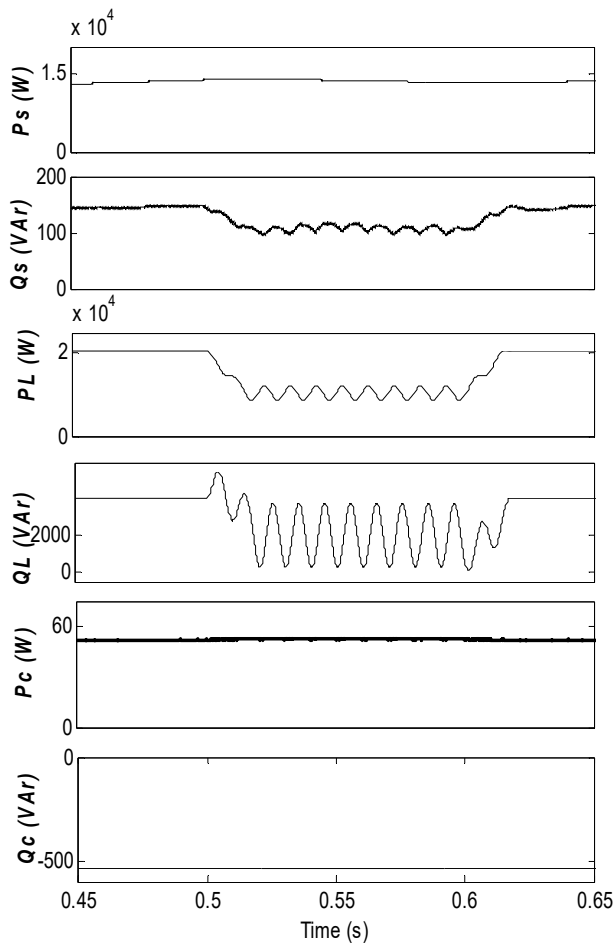

Figure 4. Active Power and reactive power variation
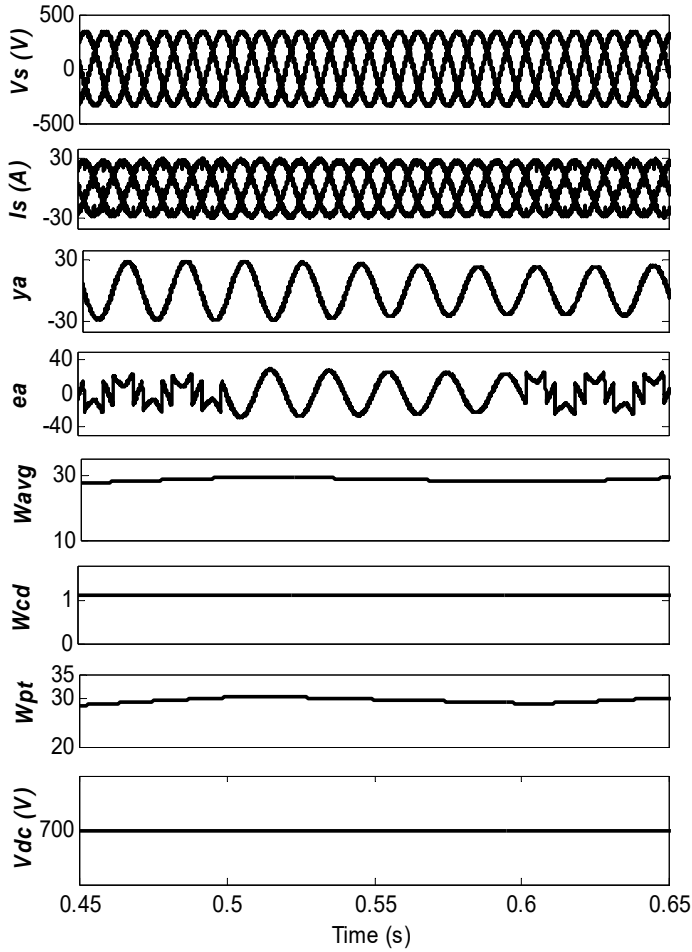

Figure 5. Variation of different parameters for nonlinear load 

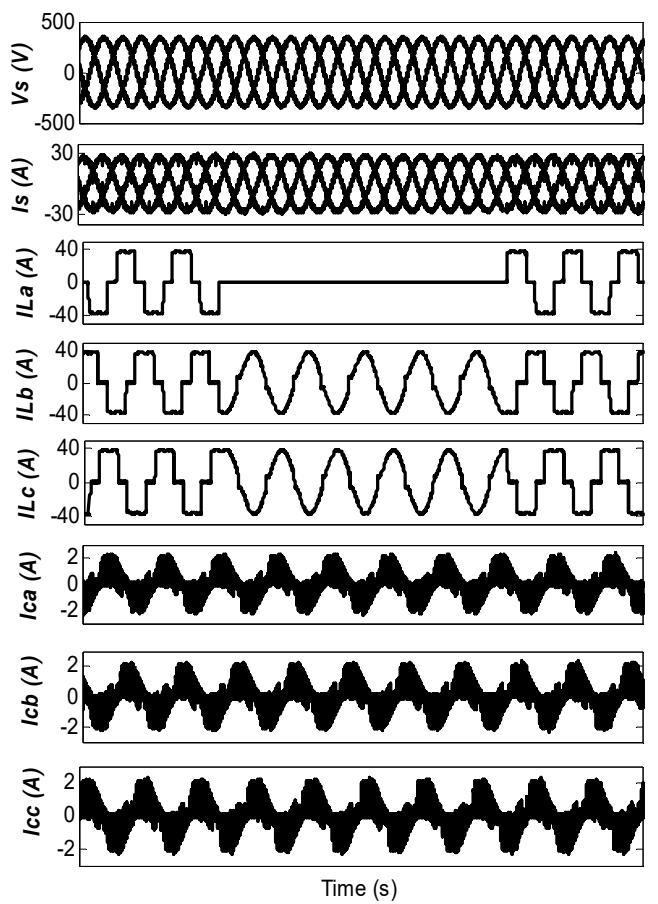

Figure 6. Load and compensator current for a nonlinear load
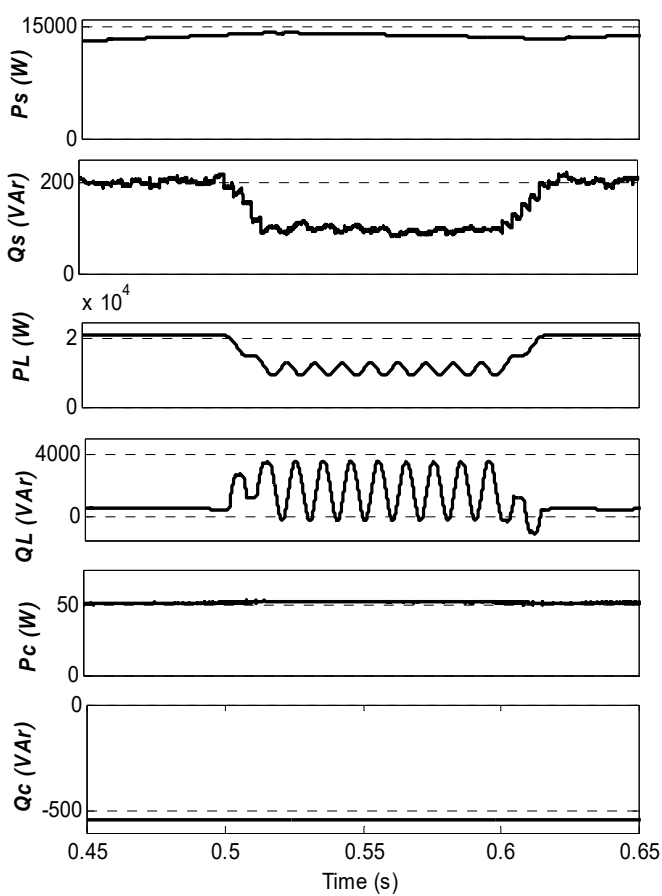

Figure 7. Active and reactive power variation for non-linear load

\section{CONCLUSION}

A three-phase adaptive filtering based DSTATCOM system is implemented to mitigate the harmonics caused by non-linear load. The active weight component extracted from load current is utilized for the gate pulse generation. The system is analyzed for both linear as well as non-linear load connected at PCC with a load disconnection of phase ' $a$ ' for a short period of time. The results for both the cases are compared and explained. The obtained results show that the control system is capable to improves many problems related to power quality like load unbalancing problem, harmonics in source current and in source voltage. The active and reactive power for load, grid and compensator is also explained with the help of a diagram, concluding that the active power to the load is mainly fed from the grid, while the reactive power comes from the compensator.

\section{APPENDIX}

Three phase AC supply: $50 \mathrm{~Hz}$, Line to line Voltage: $415 \mathrm{~V}$, Non-linear load: A diode bridge rectifier with $\mathrm{R}=15 \Omega, \mathrm{L}=10 \mathrm{mH}$, Interfacing inductors: $\mathrm{L}_{\mathrm{i}}=1.5 \mathrm{mH}$, Ripple Filter: $\mathrm{R}_{\mathrm{f}}=20 \Omega, \mathrm{C}_{\mathrm{f}}=10 \mu \mathrm{F}$, dc link Capacitor: $\mathrm{C}_{\mathrm{dc}}=4000 \mu \mathrm{F}, \mathrm{DC}$ PI controller Gain: $\mathrm{K}_{\mathrm{P}}=0.25$ and $\mathrm{K}_{\mathrm{I}}=0.1$, Reference voltage of DC link: $700 \mathrm{~V}$, Carrier wave frequency: $10 \mathrm{kHz}$.

\section{REFERENCES}

[1] A. Ghosh and G. Ledwich, "Power Quality Enhancement Using Custom Power Devices," New York, NY, USA: Springer, 2009.

[2] R. Majumder, "Reactive power compensation in single-phase operation of microgrid," IEEE Trans. Ind. Electron., vol. 60 , no. 4, pp. 1403-1416, 2013.

[3] C.S. Chen, C.H. Lin, W.L. Hsieh, C.T. Hsu, and T.T. Ku, "Enhancement of PV penetration with DSTATCOM in Taipower distribution system," IEEE Trans. Power Syst., vol. 28, no. 2, pp. 1560-1567, 2013.

[4] B. Singh and J. Solanki, "A comparison of control algorithms for DSTATCOM," IEEE Transactions on Industrial Electronics, vol. 56, no. 7, pp. 2738-2745, 2009.

[5] Sabha Raj Arya, Ram Niwas, Krishan Kant Bhalla, Bhim Singh, Ambrish Chandra, and Kamal Al-Haddad, "Power Quality Improvement in Isolated Distributed Power Generating System Using DSTATCOM, " IEEE Transactions on Industry Applications, vol. 51, no. 6, 2015 
[6] Bhim Singh and Sabha Raj Arya, "Back-Propagation Control Algorithm for Power Quality Improvement Using DSTATCOM," IEEE Transactions on Industrial Electronics, vol. 61, no. 3, 2014

[7] Sabha Raj Arya, Bhim Singh, Ram Niwas, Ambrish Chandra and Kamal Al-Haddad, "Power Quality Enhancement Using DSTATCOM in Distributed Power Generation System," IEEE Transactions on Industry Applications, vol. 52 , no. 6,2016

[8] N. G. Hingorani, and L. Gyugyi, Understanding FACTS: Concepts and Technology of Flexible AC Transmission Systems, IEEE Press, New York (USA), 2000.

[9] B. Singh, A. Chandra, and K. Al-Haddad, "Power Quality: Problems and Mitigation Techniques," Hoboken, NJ, USA: Wiley, 2015.

[10] Mohammed Asim, Mohd Tariq, M.A. Mallick and Imtiaz Ashraf, “An Improved Constant Voltage Based MPPT Technique for PMDC Motor,” International Journal of Power Electronics and Drive System (IJPEDS), vol. 7, no. 4, pp. 1330-1336, 2016.

[11] B. Singh, P. Jayaprakash, D. P. Kothari, A. Chandra, and K. Al Haddad "Comprehensive study of DSTATCOM configurations," IEEE Trans. Ind. Informat., vol. 10, no. 2, pp. 854-870, 2014.

[12] B. Singh, G. Bhuvaneswari, and S. R. Arya, "Review on Power Quality Solution Technology," Asian Power Electronics Journal, vol. 6, no. 2, pp. 19-27, 2012

[13] S. O. Haykin, "Adaptive Filter Theory," 3rd ed. Englewood Cliffs, NJ, USA: Prentice-Hall, 1996.

[14] Bhim Singh, Sabha Raj Arya, Ambrish Chandra and Kamal Al-Haddad, "Implementation of Adaptive Filter in Distribution Static Compensator," IEEE Transactions on Industry Applications, vol. 50, no. 5, 2014

[15] T. Aboulnasr, and K. Mayyas, “A robust variable step-size LMS-type algorithm: analysis and simulations, " IEEE Transactions on Signal Processing, vol. 45, no. 3, pp. 631-639, 1997.

[16] Sabha Raj Arya and Bhim Singh, "Performance of DSTATCOM Using Leaky LMS Control Algorithm", IEEE Journal of Emerging and Selected Topics in Power Electronics, vol. 1, no. 2, 2013.

[17] Y. Avargel and I. Cohen, "Adaptive nonlinear system identification in the short-time fourier transform domain," IEEE Transactions on Signal Processing, vol. 57, no. 10, pp. 3891-3904, 2009.

[18] E. A. Hermande, D. Blance, D. P. Ruiz, and M. C. Carrion, "The averaged, overdetermined, and general LMS algorithm,” IEEE Trans. Signal Process., vol. 55, no. 12, pp. 5593-5603, 2007.

[19] N. Mohan, T. M. Undeland, and W. P. Robbins, "Power Electronics: Converters, Applications and Design," 3rd ed. Hoboken, NJ, USA: Wiley, 2009.

[20] S.K. Patel, S. R. Arya and R. Maurya, "Harmonic Mitigation Technique for DSTATCOM using Continuous Time LMS Adaptive Filter," IEEE Conference on UPCON, IITBHU Varanasi, India, Dec 9-11, 2016

[21] M. Srinivas, I. Hussain and B. Singh, "Combined LMS-LMF Based Control Algorithm of DSTATCOM for Power Quality Enhancement in Distribution System," IEEE transactions on Industrial Electronics, vol. 63, no. 7, July 2016

[22] R.K. Agarwal, I. Hussain and B. Singh, "LMF-Based Control Algorithm for Single Stage Three-Phase Grid Integrated Solar PV System," IEEE Transactions on Sustainable Energy, vol. 7, no. 4, October 2016

Int J Pow Elec \& Dri Syst Vol. 10, No. 4, Dec 2019 : 1944 - 1950 